\title{
Utilizando o Scratch como ferramenta de apoio para desenvolver o raciocínio lógico das crianças do ensino básico de uma forma multidisciplinar
}

\author{
Esteic Janaina S. Batista ${ }^{1,2}$, Amaury A. Castro Jr. ${ }^{1,2}$, Cintia Adriana C. Bogarim ${ }^{1}$, \\ Andreia A. Larrea ${ }^{1}$ \\ ${ }^{1}$ Universidade Federal de Mato Grosso do Sul - Campus Ponta Porã (CPPP) \\ Rua Itibiré Vieira, s/n - Residencial Julia Oliveira Cardinal BR 463 - Km 4,5 \\ ${ }^{2}$ Bolsistas do Programa de Educação Tutorial - PET/SESu/MEC
}

\{esteicejanaina, amaury.ufms\}@gmail.com, \{ cintiabogarim, andreiaalfonso\}@hotmail.com

\begin{abstract}
This work aims to present a workshop on Scratch tool for teachers of technology rooms and multipliers of public schools in Ponta Porã. State of Mato Grosso do Sul, so that it can be used in the classroom, since allowing it to be used in different disciplines, and teach programming concepts in a fun and unconsciously. Scratch favors the development of logical reasoning of the student, which can result in better test scores of OBI and OBR for example, requiring the participant the ability to solve problems and challenges; and in Logical Reasoning discipline.
\end{abstract}

Resumo. Este trabalho tem como objetivo apresentar a oficina sobre a ferramenta Scratch para professores das salas de tecnologia e multiplicadores das escolas públicas da cidade de Ponta Porã, no estado de Mato Grosso do Sul, para que ela possa ser utilizada em sala de aula, uma vez que permite ser utilizado em diferentes disciplinas, e ensinar conceitos de programação de forma divertida e inconsciente. O Scratch favorece o desenvolvimento do raciocínio lógico do aluno, que pode resultar em melhores notas nas provas da OBI e OBR por exemplo, que exigem do participante a capacidade de resolver problemas e desafios; e também na disciplina de Raciocínio Lógico.

\section{Introdução}

$\mathrm{Na}$ última década observamos um crescente aumento no número de ferramentas tecnológicas que auxiliam no processo de ensino-aprendizagem nas escolas, permitindo inserir as TICs (Tecnologias da Informação e Comunicação) na sala de aula.

Porém, não basta o professor utilizar estas novas tecnologias com as mesmas práticas tradicionais, onde o aluno é restrito ao conhecimento que é transmitido a ele em sala de aula, em que não desenvolve sua capacidade de aprender determinado conteúdo a partir de suas próprias experiências, pois tais práticas não caracterizam mudanças reais no processo de ensino-aprendizagem. É preciso repensar as novas formas de ensino em um contexto que o professor é apenas um mediador do conhecimento, permitindo a colaboração e cooperação entre a turma, apresentando-lhes situações que desenvolvem sua capacidade de resolver problemas.

De acordo com [Moran 1997], o movimento tecnológico tem influenciado e transformado as formas do indivíduo se comunicar, transmitir informações $\mathrm{e}$ consequentemente as suas relações sociais que também influem nas escolas. As 
tecnologias tornam mais atraente, aos alunos, a aprendizagem, mas implicam no desafio para a educação, pois essas novas tendências exigem que as escolas inovem e reorganizem seu modelo de ensino.

Uma das formas que pode auxiliar o professor a estimular os alunos o aprender a aprender, é por meio de utilização de ferramentas, como o Scratch, que permite criar jogos, animações e histórias, desenvolvendo o raciocínio lógico, ensinando programação e permitindo que seja utilizado de uma forma multidisciplinar.

Neste contexto, este trabalho descreve uma oficina do Scratch oferecida para os professores da sala de tecnologia das escolas de Ponta Porã, onde é apresentado as possibilidades de utilizar esta ferramenta como um Objeto de Aprendizagem no ensino básico de uma forma multidisciplinar. Isto permite, que ele possa ser usado, por exemplo, como auxílio na disciplina de Raciocínio Lógico, que é uma nova disciplina obrigatória para alunos a partir do $6^{\circ}$ ano do ensino fundamental do regime de 9 anos e para todo o ensino médio.

Com esta ação, espera-se que os alunos desenvolvam a lógica, melhorando o seu desempenho nas provas da Olimpíada Brasileira de Informática (OBI) e Olimpíada Brasileira de Robótica (OBR) que possuem questões que exigem do aluno raciocínio lógico para resolvê-las; uma vez que o número de inscritos vem crescendo a cada ano no estado de Mato Grosso do Sul (MS) e, em especial, em Ponta Porã.

$\mathrm{Na}$ Seção 2, apresentaremos sobre a estrutura da Universidade na qual este projeto é desenvolvido e do programa de extensão da Universidade em que ele é vinculado. Na Seção 3, vamos apresentar um pouco de duas olimpíadas científicas que exigem raciocínio lógico e conceitos sobre programação e robótica, e como a cidade de Ponta Porã tem se destacado em número de inscrições nacionalmente. Nas Seções 4 e 5, são apresentadas, respectivamente, os Núcleos de Tecnologias Educacionais da cidade, e sobre a nova disciplina de Raciocínio Lógico.

Por fim, nas últimas seções são apresentados o Scratch e a oficina oferecida sobre esta ferramenta para os professores, além dos resultados esperados e considerações finais.

\section{Estrutura da Universidade}

O projeto está sendo desenvolvido na Universidade Federal de Mato Grosso do Sul na cidade de Ponta Porã, região que faz fronteira seca com o Paraguai. Os cursos oferecidos no campus são: Sistemas de Informação, Ciência da Computação, Matemática e Pedagogia. Isto possibilita a integração entre esses cursos e favorece uma formação diferenciada, pois quem é da área mais pedagógica, como Matemática e Pedagogia tem esse contato com a tecnologia, e como serão os futuros professores do ensino básico, poderão levar para sala de aula estas experiências. Por outro lado, quem é da área tecnológica pode trocar experiências com os acadêmicos da área pedagógica e cooperar em projetos multidisciplinares, como os projetos existentes na unidade de robótica educacional, desenvolvimento de Objetos de Aprendizagem, entre outros.

A construção de um profissional e de um cidadão consciente passa por um processo de formação que se apresenta com características bem interessantes, 
inovadoras e motivadoras, no que diz respeito às condições didático-pedagógicas. Devem ser criadas situações onde os alunos possam utilizar a sua criatividade participando da construção de programas de computador, robôs, despertando a curiosidade e inúmeras vocações que se manifestam muitas vezes em ambientes propícios e que ofereçam a estrutura adequada para este desenvolvimento. O programa NERDS da Fronteira (Núcleo Educacional de Robótica e Desenvolvimento de Software) surge como uma alternativa inovadora para a promoção desse ambiente, envolvendo acadêmicos de todos os cursos oferecidos no Câmpus de Ponta Porã da UFMS.

Os objetivos do programa são ampliar as oportunidades de formação educacional e de qualidade para alunos, professores e demais membros da sociedade local, por meio de oficinas, treinamentos, eventos, treinamento de alunos e professores para Olimpíadas Científicas como a OBI e a OBR, entre outras atividades de extensão. Dessa forma, pretende-se formar profissionais habilitados para fazer uso e se adaptar às novas tecnologias e atuar em diferentes formas de trabalho decorrentes da dinâmica evolutiva da sociedade atuais, como atividades que incluem robótica educacional e tecnologias educacionais [Fistarol 2015].

\section{Olímpiadas Científicas}

O estado de Mato Grosso do Sul tem tido cada vez mais participação em Olimpíadas Científicas como a OBI e a OBR, o que têm destacado o estado nacionalmente e internacionalmente.

As olimpíadas científicas são uma iniciativa para a popularização e difusão da ciência e tecnologia junto aos jovens utilizada em praticamente todo o mundo. Além da difusão, as olimpíadas realizam muitas outras atividades, e, em muitos casos são também atores no processo de atualização dos professores e escolas.

A Olimpíada Brasileira de Robótica (OBR) é uma das olimpíadas científicas brasileira que utiliza a temática da robótica para estimular estudantes às carreiras científico-tecnológicas, identificar jovens talentosos e promover debates e atualizações no processo de ensino-aprendizagem brasileiro. A OBR possui duas modalidades, prática e teórica, para adequar-se tanto ao público que nunca viu robótica quanto ao público de escolas que já têm contato com a robótica educacional [OBR 2015].

A Olimpíada Brasileira de Informática (OBI) tem como objetivo despertar nos alunos o interesse por uma ciência importante na formação básica hoje em dia (no caso, ciência da computação), através de desafios apresentados na forma de duas modalidades da olimpíada: iniciação e programação [OBI 2015].

Na OBI, a participação do estado de MS é crescente a cada ano (Figura 1), tendo sua primeira participação em 2010 com aproximadamente 100 inscritos, e mais de 3500 inscritos neste ano. 


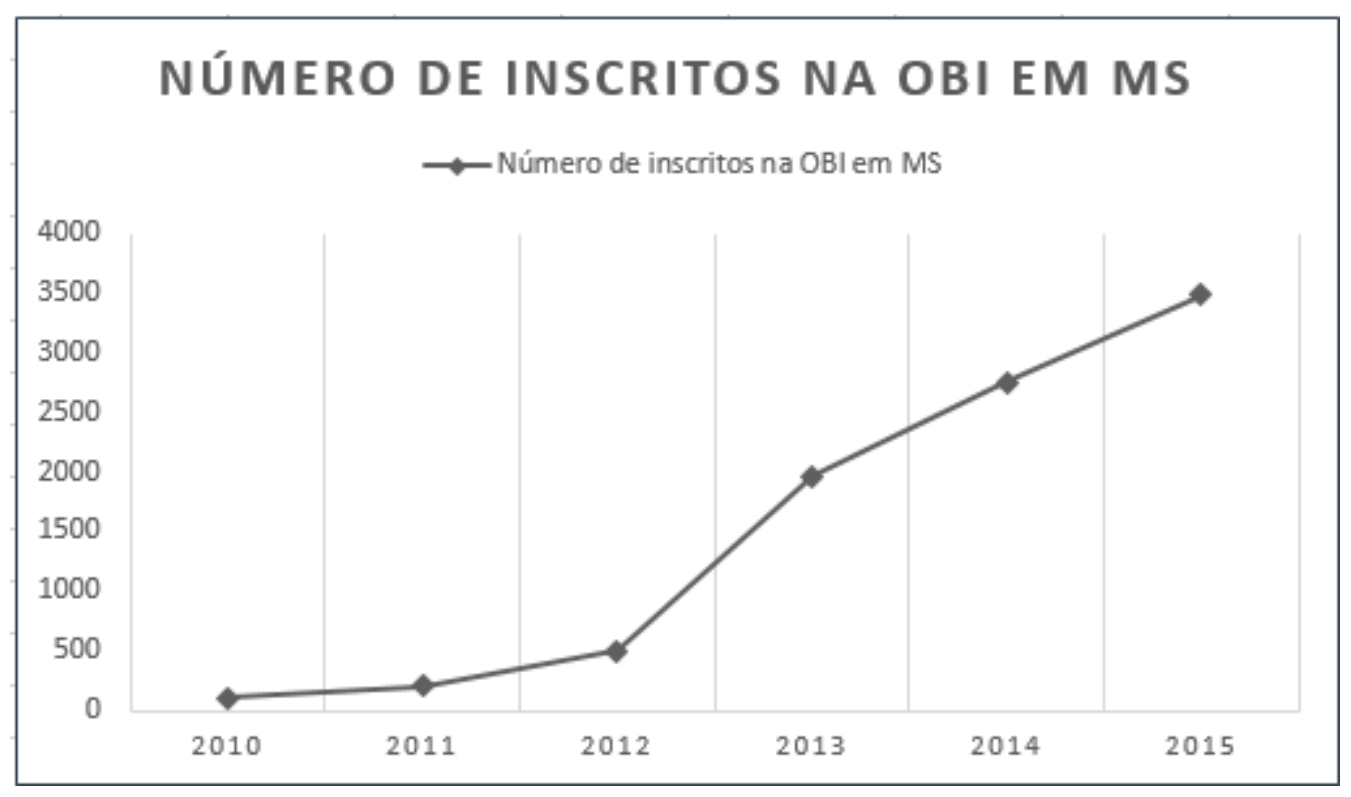

Figura 1 - Gráfico do número de inscritos na OBI em MS

No entanto, ao comparar o gráfico da Figura 1 com o gráfico da Figura 2, mais de $90 \%$ dos inscritos são da cidade de Ponta Porã. Esse número é resultado dos vários projetos e ações de extensão realizadas pelo grupo do programa NERDS da Fronteira, que vem estimulando a participação destas escolas.

O mais interessante é que a escola de Ponta Porã com maior participação, tratase de uma escola de assentamento, onde 1100 alunos foram inscritos neste ano, o que caracteriza uma democratização do acesso ao ensino na cidade.

Embora o número de inscritos tenha crescido significativamente a cada ano, poucos apresentam um desempenho suficiente para destacarem-se nacionalmente. Nesse contexto, a oferta de oficinas, através do programa NERDS, apresenta-se como uma alternativa para capacitar os professores, e assim estes treinarem os alunos das respectivas escolas para as olimpíadas, para que estes possam obter melhores notas e difundir ainda mais a participação dos alunos do ensino básico em olimpíadas cientificas.

Há também, como objetivos dessas ações, que os alunos comecem a programar desde o ensino básico, por estimular a compreensão e resolução de problemas e o raciocínio lógico das crianças. Além disso, aumentar a procura pelos cursos tecnológicos, como Sistemas de Informação e Ciência da Computação, bem como prepará-los melhor para o Ensino Superior, incentivando os professores a realizarem projetos com os alunos aplicando o conhecimento destas tecnologias. 


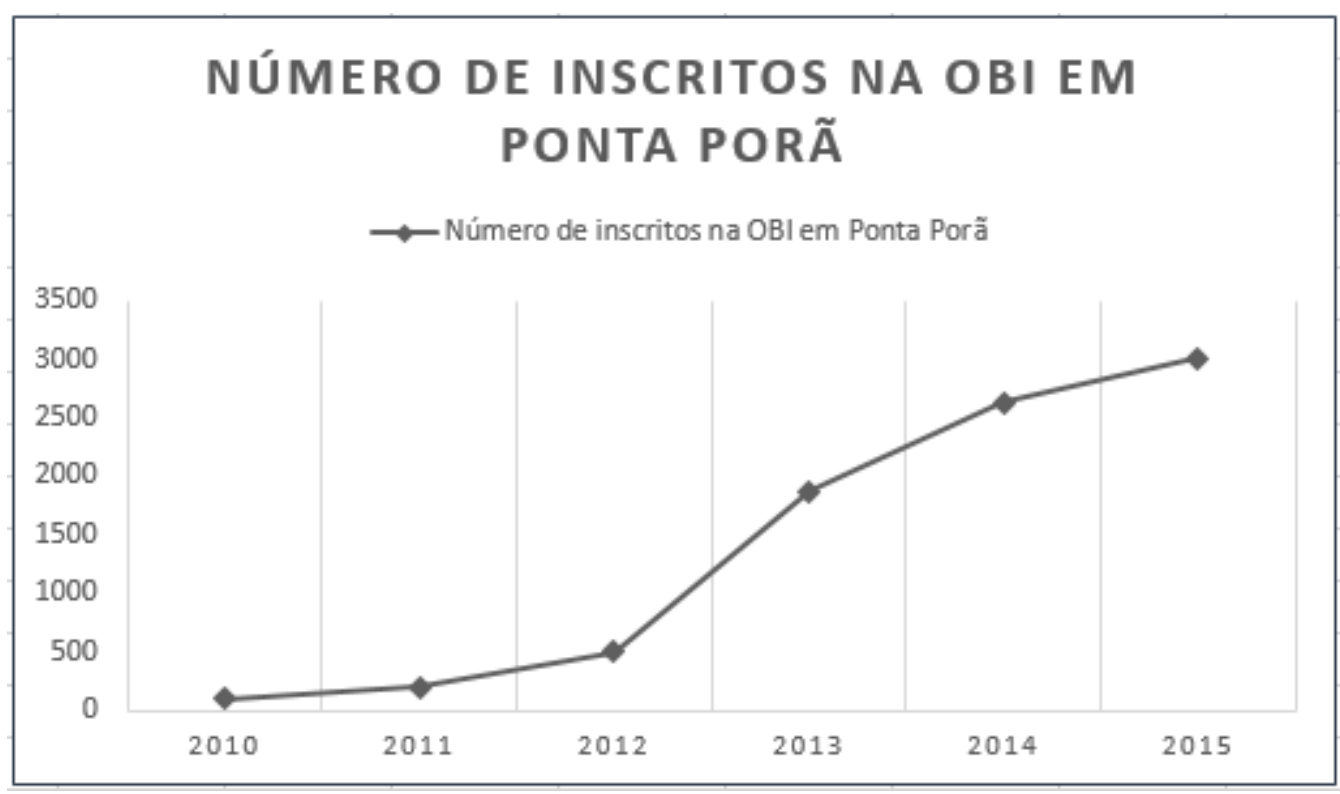

Figura 2 - Gráfico do número de inscritos na OBI em Ponta Porã

\section{Núcleos de Tecnologias Educacionais.}

Os Núcleos de Tecnologia Educacionais (NTEs) são ambientes computacionais com equipe interdisciplinar de professores multiplicadores e técnicos qualificados, para dar formação contínua aos professores e assessorar escolas da rede pública (Estado e Município), no uso pedagógico bem como na área técnica (hardware e software).

Em Ponta Porã, o NTE e o NTE Municipal (NTEM) têm parceria com a UFMS campus Ponta Porã desde a implantação dos primeiros cursos na unidade em 2010; para que por meio de programas, como o NERDS e seus projetos de extensão possam oferecer oficinas de capacitação para os professores multiplicadores e da sala de tecnologia das escolas, incentivá-los e dar o apoio necessário para a realização de olimpíadas científicas.

\section{Disciplina de Raciocínio Lógico}

A disciplina de Raciocínio Lógico tornou-se obrigatória ano passado para os anos finais do ensino fundamental e o ensino médio das escolas. A Secretaria do Estado de Educação de MS, apresentou os componentes curriculares da disciplina que deve ser planejado de acordo com a matriz curricular das séries obrigatórias, e como trabalhar com os anos iniciais do ensino fundamental.

Segundo os componentes curriculares da disciplina de Raciocínio Lógico, o professor deve trabalhar com o aluno a capacidade de resolver problemas, aplicando a Matemática e deixando que ele pense por si mesmo, de forma multidisciplinar, ou seja, abordando parâmetros curriculares de outras disciplinas.

O professor de Raciocínio Lógico, deve ainda, escolher atividades estimulantes e desafiadoras, para que o estudante encontre alternativas para resolver os problemas. 
Esse conteúdo pode ser abordado utilizando softwares, hardware, jogos, problemas de raciocínio lógico, dentre outros.

Esta nova disciplina é um grande avanço para a educação no ensino básico, uma vez que, o raciocínio lógico é essencial para qualquer tipo de Ciência e para a vida, pois desenvolve a estruturação do pensamento para a resolução de qualquer problema. A criação desta disciplina, torna obrigatório o que já deveria estar sendo ensinado as crianças desde as séries iniciais em todas as disciplinas.

No entanto, muitos professores, ainda não possuem o domínio das ferramentas necessárias para desenvolver esta capacidade nas crianças. Os integrantes do programa NERDS da Fronteira vêm estudando diversas ferramentas, para ensinar os professores por meio de oficinas, para que estes possam aplicá-las em sala de aula, em especial na disciplina de Raciocínio Lógico, uma vez que esta deve ser trabalhada de forma multidisciplinar ensinando conceitos de matemática e outras disciplinas, além de ensinar inconscientemente conceitos de programação para crianças, alcançando o objetivo de desenvolver o raciocínio lógico.

A primeira oficina será sobre a ferramenta Scratch que permite trabalhar a ementa de Raciocínio Lógico, pois de acordo com [Mota 2014] todo software pode ser considerado educacional, desde que sua utilização esteja inserida num contexto e em uma situação de ensino-aprendizagem, favorecendo seu desenvolvimento e propiciando meios que enriquecem a prática docente.

\section{O Scratch}

O Scratch é um projeto do grupo Lifelong Kindergarten no Media Lab do Instituto de Tecnologia de Massachusetts (MIT) dos Estados Unidos. É uma ferramenta gratuita desenvolvida para crianças e adolescentes, mas que vem sendo utilizado por pessoas de diferentes faixas etárias, que permite que seja aplicado em uma série de diferentes projetos pedagógicos, que possibilita crianças e jovens a aprenderem programação desde cedo. 


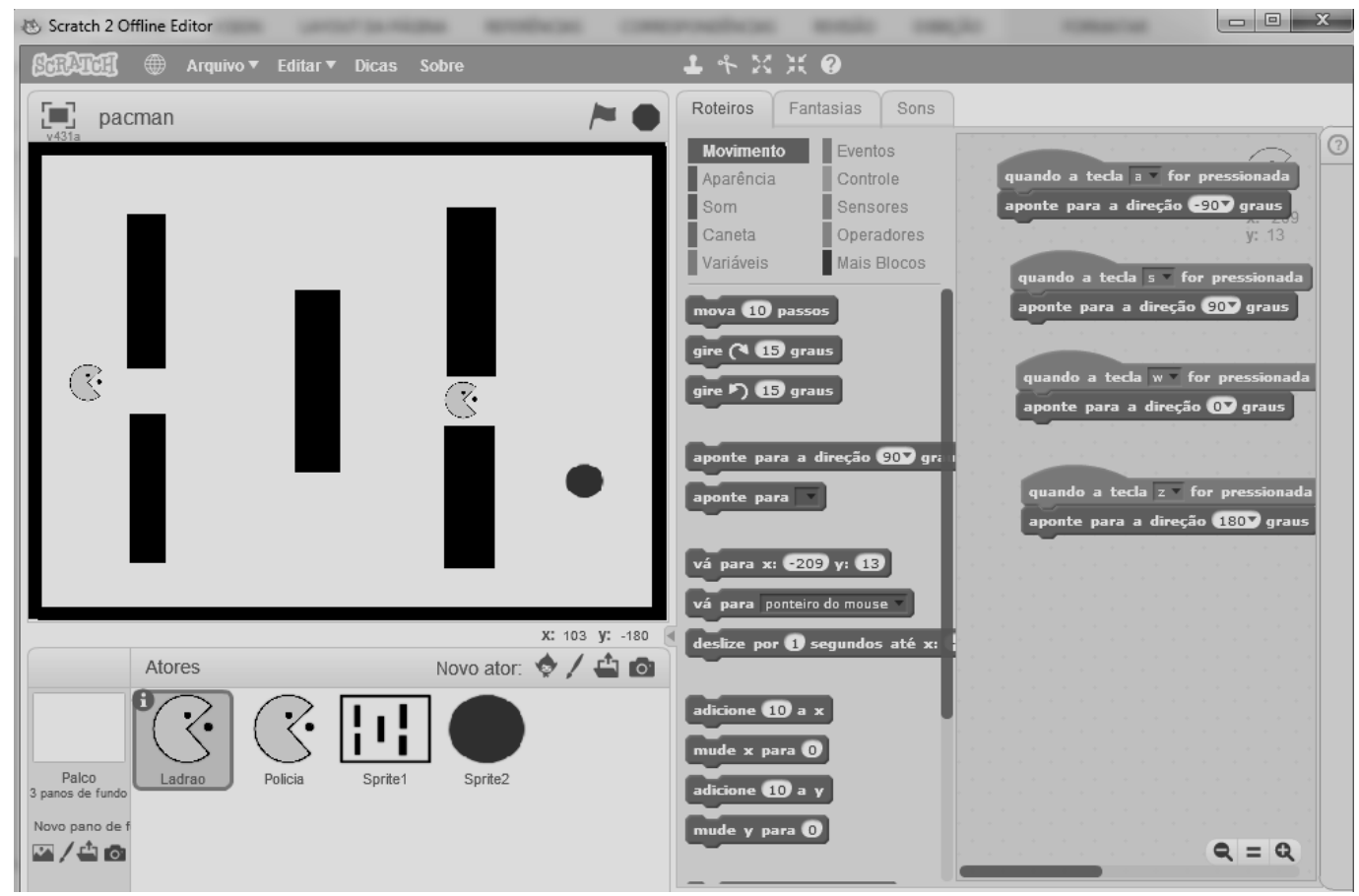

Figura 3 - Ambiente de Desenvolvimento Scratch

Baseado na linguagem LOGO, ele possui códigos simples para comandar o personagem por blocos, que permitem serem encaixados para criar uma aplicação, o que lembra os brinquedos de encaixar Lego, baseado no conceito de drag-and-drop (arrastar e largar).

A ferramenta permite criar jogos, animações e histórias, em um ambiente intuitivo, divertido e fácil, possibilitando que o usuário altere o cenário, personagem, inclua sons, utilize a câmera, permitindo ser usado nas mais diferentes disciplinas.

\section{Trabalhos Relacionados}

Há vários projetos que utilizam o Scratch, porém a maioria aplica a ferramenta voltada para o ensino da programação, sem relacionar com outras áreas.

No trabalho de [Dias e Serrão 2014] é relatada a experiência do uso da Linguagem Scratch com alunos ingressantes de um curso de Computação, com objetivo de tornar mais simples o contato destes com algoritmos e um melhor entendimento sobre os conceitos de programação.

Já [Motta et al. 2014] propõem em seu trabalho a aplicação de um curso de lógica de programação por meio da ferramenta Scratch para adolescentes do ensino médio em uma escola pública.

Por fim, no trabalho de [Martins 2012] é apresentado a dissertação que relata a experiência do ensino de uma oficina para crianças com potencializar o pensamento criativo em crianças do ensino fundamental.

\section{Oficina de Scratch para os professores}


A oficina do Scratch será ofertada para os professores das salas de tecnologia das escolas estaduais e municipais. Esta acontecerá presencial e virtualmente, utilizando recursos da Educação a Distância $(\mathrm{EaD})$, sendo que em um dia de cada semana haverá o encontro presencial.

$\mathrm{Na}$ oficina será apresentado a esses professores o ambiente do Scratch, alguns conceitos de programação, e as possibilidades de aplicar a ferramenta nas diferentes disciplinas, com grande enfoque na disciplina de Raciocínio Lógico.

Como dito anteriormente, foi decidido dar ênfase a disciplina de Raciocínio Lógico por esta conter uma grade curricular que permite que o Scratch seja utilizado como ferramenta de apoio em todo o seu andamento, e também por possuir esse caráter multidisciplinar.

Na matriz curricular de Raciocínio Lógico, no geral, tem-se medidas de tempo, procedimentos de decisão, enigmas, jogos, desafios, raciocínio lógico quantitativo e com problema de correlacionamento, introdução à lógica, estrutura e diagramas lógicos, lógica e argumentação, sequências numéricas, conteúdos de Matemática, dentre outros, que permitem ser exemplificados e explicados utilizando o Scratch, permitindo que o aluno veja a aplicação prática do conteúdo, e assimilando melhor a outros elementos de seu cotidiano.

A vantagem de utilizar a ferramenta do Scratch na disciplina de Raciocínio Lógico, é que ela permite ser empregada em conceitos de outras disciplinas, como Educação Artística, por meio da criação de personagens e cenários, Geografia, por meio de sensores, além do ensino da programação e de uma série de outras disciplinas que permitem o aluno a pensar e desenvolver aplicações que relacionarem com outros conteúdos.

Conforme [Martins 2012], entre as metodologias de aprendizagem adotadas no Scratch estão: noções básicas sobre computadores e programação, necessidade de indicar ao computador exatamente o que deve ser feito, passo por passo, e a não exigência de perícia especial, apenas de raciocínio claro e cuidadoso.

Para [Moraes 1997], o simples acesso à tecnologia, em si, não é o aspecto mais importante, mas sim, a criação de novos ambientes de aprendizagem e de novas dinâmicas sociais a partir do uso dessas novas ferramentas. Sendo assim, é preciso conhecer e saber apropriar as diferentes ferramentas computacionais na educação. E é devido a isso, que resolvemos capacitar os professores para utilizar o Scratch.

\subsection{Estrutura da Oficina.}

A oficina será estruturada da seguinte forma: aulas presenciais quinzenais e aulas virtuais no Ambiente Virtual de Aprendizagem (AVA) Moodle.

No Ambiente Virtual de aprendizagem Moodle, cada tópico tem uma vídeo-aula sobre cada categoria de blocos do Scratch: movimento, aparência, som, caneta, variáveis, evento, controle, sensores, operadores, blocos e extensões para Lego e Arduino. Haverá ainda uma atividade que aborde os conceitos apresentados no presente tópico, um documento com explicações detalhadas sobre determinado blocos, além de 
um desafio. Há ainda os tópicos de apresentação, e outros dois tópicos que se tratam de projetos utilizando o Scratch e informações sobre o trabalho final da Oficina.

Este trabalho final consiste em um projeto que o professor deverá desenvolver na escola com um grupo de alunos, onde deverá abranger conceitos de alguma disciplina. Este projeto deverá ser apresentado pelo professor juntamente com os alunos que participaram do desenvolvimento do projeto, além de ter que ser entregue um pequeno documento, similar a um artigo.

Com o projeto final da oficina pretende-se proporcionar aos professores e alunos o contato com a pesquisa, aplicando o conhecimento obtido na Oficina, para que motive outros professores e alunos, destacando, assim, o nome da cidade não somente em olimpíadas científicas, mas também em feiras de Ciências, que é onde terão oportunidade de apresentar tudo o que aprenderam e conseguiram desenvolver a partir destas ações.

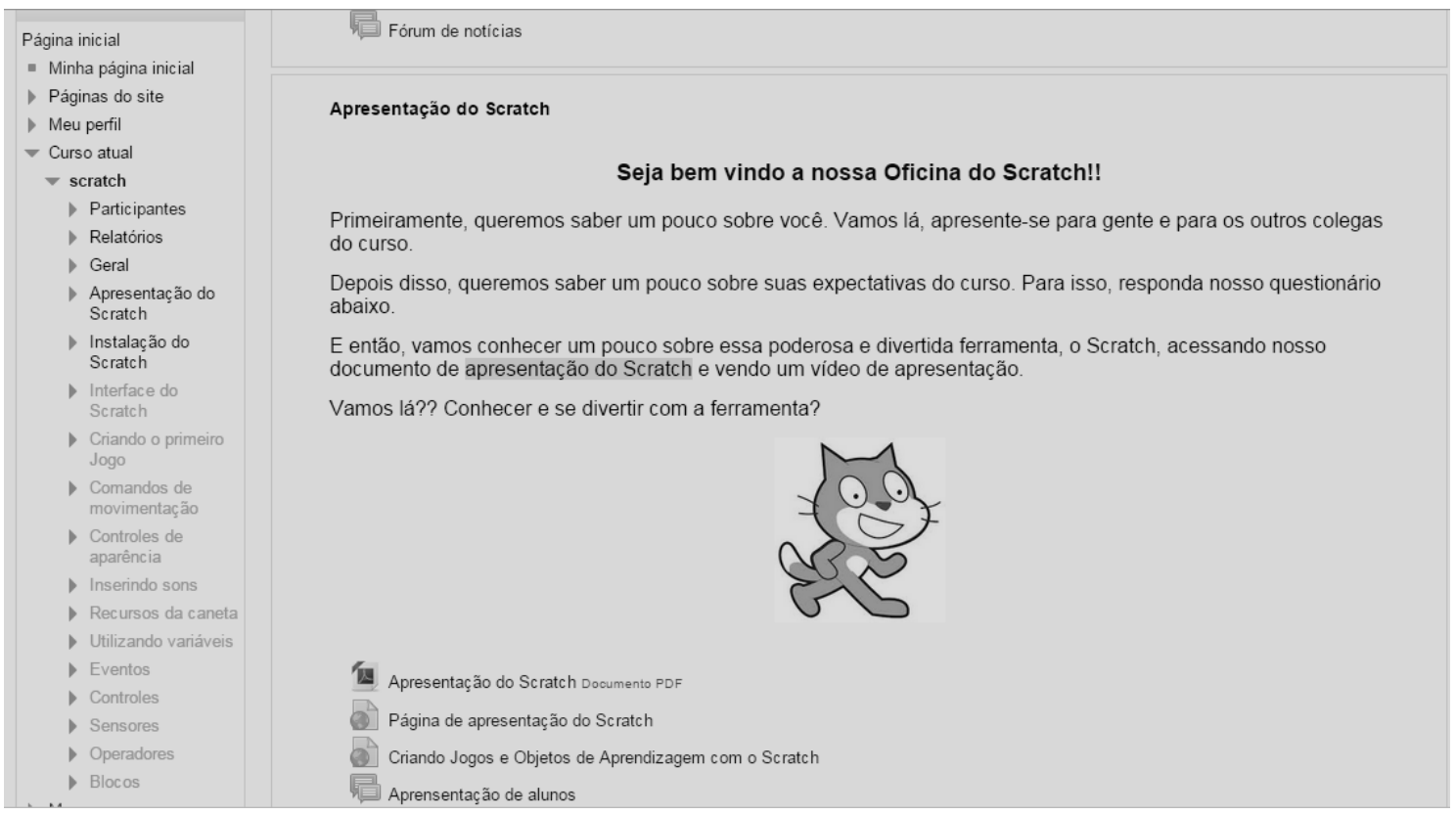

Figura 4 - Sala do curso do Scratch no Moodle

As aulas serão no NTE para professores das escolas estaduais e no NTEM para professores das escolas municipais, e irão abordar os tópicos apresentados na sala Moodle, tirar dúvidas e desenvolver as atividades.

\section{Considerações Finais}

O Scratch apresenta-se como uma poderosa ferramenta para ser aplicada no ensino básico, para ensino de conceitos de programação, por ser intuitivo. Ele caracteriza-se em um Objeto de Aprendizagem (OA), que de acordo com [Braga 2013] deve auxiliar o professor a criar novas estratégias pedagógicas que favoreçam o aprendizado do aluno e apesar de ser um desafio, espera-se que um mesmo OA possa ser reutilizado em diferentes contextos educacionais.

Podemos observar que o Scratch apresenta todas as características inerentes de um OA, permitindo ser utilizado em diferentes disciplinas, para diferentes finalidades, sendo que em todas essas desenvolvem o raciocínio lógico das crianças que podem criar 
algo em uma área que se identifique e ao mesmo tempo aprendendo conceitos de programação.

Espera-se que essa oficina seja replicada pelos professores da sala de tecnologia e multiplicadores para os demais professores das suas respectivas escolas. E ainda, que aumente o interesse dos alunos por tecnologia para que que criem seus próprios jogos, animações, dentre outras, utilizando conceitos de programação e relacionando-os com conteúdo vistos em sala de aula, em diferentes disciplinas.

O Scratch é apenas o primeiro passo de uma série de outras capacitações e oficinas que o programa NERDS pretende realizar. Está prevista outras como capacitações para professores poderem oferecerem treinamento para os alunos para olimpíadas e competições na área de informática e robótica, apresentações de outras ferramentas, como o RoboMind, programação para robôs Lego, softwares para desenvolvimento de aplicações para dispositivos móveis como o App Inventor, dentre outras ações, que vem sendo desenvolvidas pelo programa.

\section{Referências}

Braga, J. C., Pimentel, E., e Dotta, S. (2013). Metodologia INTERA para o desenvolvimento de Objetos de Aprendizagem. XXIV Simpósio Brasileiro de Informática na Educação (SBIE 2013).

Dias, K. L. e Serrão, M. L. (2014). A Linguagem Scratch no Ensino de Programação: Um Relato de Experiência com Alunos Iniciantes do Curso de Licenciatura em Computação. XXXIV Congresso da Sociedade Brasileira de Computação.

Fistarol, D. O. et. Al. (2015). Programa NERDS da Fronteira e o uso da Robótica Educacional na Inclusão Digital. Computer on the Beach 2015.

Martins, A. R. Q. Usando o Scratch para potencializar o pensamento criativo em crianças do ensino fundamental. Dissertação de Programa de Pós-Graduação em Educação. Disponível em: http://www.upf.br/ppgedu/images/stories/defesa-dissertacaoamilton-rodrigo-de-quadros-martins.PDF. Acesso em: maio de 2015.

Moran, J. M. (1997). Como utilizar a Internet na educação. Disponível em: http://www.scielo.br/scielo.php?pid=s0100-19651997000200006\&script=sci_arttex.

Acesso em: maio de 2015.

Moraes, M. C. Subsídios para Fundamentação do Programa Nacional de Informática na Educação. Disponível em: http://www.discussoessobreainserçãodastecnologia.br/dmd2.webfactional. Acesso em: maio de 2015.

Motta, F. P. et al. (2014). Desenvolvendo o Raciocínio Lógico no Ensino Médio: uma proposta utilizando a ferramenta Scratch. XXV Simpósio Brasileiro de Informática na Educação. 